\title{
The Role of Safety Training in Original Equipment Manufacturing Companies on Employee Perception of Knowledge, Behavior Towards Safety and Safe Work Environment
}

\author{
Ravi Sharma*, Dharmesh K. Mishra
}

Symbiosis Institute of International Business, Symbiosis International (Deemed University), Hinjawadi Phase 1, Pune 411057, Maharashtra, India

Corresponding Author Email: ravi.sharma@siib.ac.in

https://doi.org/10.18280/ijsse.100514

Received: 2 August 2020

Accepted: 26 September 2020

\section{Keywords:}

safety training, work environment, supervisor role, influence of training, safety culture

\begin{abstract}
Training is important for the development of skills and knowledge. The purpose of this study was to explore the influence of post- safety training on the supervisors learning process, behaviour towards safety and development of safe work environment in the automotive original equipment manufacturing (OEM) companies. In the present study, a total of 129 supervisor level employees from different Indian automotive OEMs units, who have undergone a minimum of one-day safety training in the past three years, were a part of the survey. The survey was administered with the aid of a pre-validated designed questionnaire (developed in consultation with industry experts) to collect responses from the supervisor's level employees during the period of January- August 2019. The 63 different manufacturing OEM automotive units from the Delhi- NCR and Pune- Nashik Kolhapur from Western region agreed to participate in the survey. The results obtained were tested using multiple hierarchical regression analysis in a stepwise method, along with the correlation coefficient analysis. The results indicated that knowledge acquisition, learning process, and employee involvement regarding risks and hazards identification were positively related to the perceived effectiveness of post- safety training by the supervisors. It was further found that the post- safety training has no significant contribution towards the perceived self- behavior change and development of safe work environment. The effectiveness of safety training and development of safe environment along with the change in behavior towards the safety is related to factors such as related education in safety and health, working experience in the field of safety or EHS domain and knowledge of the supervisors gained through their career which play a significant role. A safety culture can be created by the organization by harnessing the safety-related work experience of the supervisors and periodically conducting the skill development program.
\end{abstract}

\section{INTRODUCTION}

Occupational safety and health (OSH) of workers has gained prominence on account of rapid globalization and industrialization. As the fourth industrial revolution gains prominence, $\mathrm{OSH}$ training needs to be aligned with industry 4.0 norms and various stakeholders [1]. Adhering to $\mathrm{OSH}$ practices ensures that risk factors at the workplace reduce and the workers and organizational assets are well protected against personnel and economic losses. According to Dorman [2], the fatality rate due to work-related accidents and injuries are more than one million annually as per the statistics revealed by the International Labor Organization (ILO). ILO further states that the human casualties on account of workplace incidents are more than road accidents, war, violence, and human immunodeficiency virus (HIV) causalities. Several thousand workers also suffer from workrelated accidents and occupational exposure to hazardous substances. This can lead to long term ailments such as cancer, cardiovascular, respiratory, and nervous-system disorders amongst the workers. The death and injury toll is higher in developing countries on account of a large number of workers engaging in risky and hazardous activities such as construction, mining, etc. This figure is in stark contrast to developed nations where the fatality rate is half of the developing countries [3]. It is estimated that six lakh lives can be saved if organizations start using and implementing OSH practices prevalent in their sector [2]. The practices ought to be designed by catering to the employee workplace safety needs. Organizational commitment to workplace safety by designing employee-centric safety policies influences the level of employee engagement and adherence to occupational health and safety [4]. The designed policies need to be integrated with the work processes to accentuate the importance of the same. The introduction of health and safety management systems and processes has helped in the reduction of accidents and deaths. These systems can be more effective in organizations if they are supported by a positive safety workplace culture [5]. A safe workplace culture results in a win-win solution for both the organization and its employees. When employees have a positive perception of organizational systems, communication, and training, they willingly comply with safety rules and procedures [6]. The perception can be further reinforced by conducting additional OSH training for all employees at regular intervals. Exposure to OHS training was found to increase awareness of OHS in a large group of occupations. 
Active training methods were found to create a greater impact on awareness than passive training methods [7]. The training methods used needs to be able to meet and adapt to the participant's needs. The use of visual training methods in safety training resulted in higher employee satisfaction [8]. The trained employees can further retrain their workforce to create a healthy and safe work environment. Aziz and Osman [9], found that employees use their post-OSH training knowledge at their workplace to foster a more effective safety culture.

The presence of health and safety committees in organizations for meetings and discussions on safety also helped reduce accidents [10]. Gender, age, and education play a detrimental role in the formation of safety attitudes of employees [11]. As the education, age, and experience of employees vary in an organization the OSH training ought to incorporate these aspects in the design stage for more effective and meaningful delivery of safety modules [12]. The prevalence of fatal accidents amongst older workers is higher than younger workers. Thus, OSH training emphasizes to be more focused on older workers [13]. Safety regulations should be supplemented by education and training for better adherence to occupational safety and health [14]. With increasing stress on production on account of globalization, there is always a conflict between production and adherence to safety norms. With increasing competition, demand for a particular product is short-lived, which can lead to job losses amongst workers. Job insecurity amongst employees is also known to add to a detrimental safety culture at the workplace [15].

\section{THEORETICAL BACKGROUND HYPOTHESES \\ 2.1 Safety training and employee's knowledge and learning process}

Safety performance at work has been found to be positively related to safety training and the quality of safety information available to employees [16]. Such training help in ensuring a congenial safety culture and higher employee motivation for adherence to safety practices. Leadership commitment and support to safety training are also crucial towards encouraging the right behaviours amongst workers [17]. The line manager's support of the safety professional in implementing safety training initiatives at the workplace is crucial in creating a positive safety culture [18]

The workers who are a part of a positive safety work culture and environment usually demonstrate a higher level of hazard identification and safety perception [19]. The workplace can be a mix of local and foreign workers. Local workers have a higher perception of management commitment to safety in comparison to foreign workers [20]. Worker attitude is an important aspect of adopting safe behaviours at work. At the workplace, the employee's risk perception of self was found to be positively correlated to employee attitude [21]. The demographic profile of the workers also influences their perception of safety-related training. The age, education, and knowledge of workers have a significant impact on worker attitude and perception of safety training $[11,12]$. In small and medium enterprises (SMEs) greater attention to safety training with management support helps in building a better safety climate and perception $[22,23]$. Top management support is also crucial in creating a safe work culture. Leaders who are perceived as a role model at the workplace can help enhance safety perception by their ability to communicate and accentuate the importance of safety programs [24]. The use of mobile devices in safety training assisted employees in acquiring safety related knowledge [25]. Using game-based safety training modules improved employee learning effectiveness and safety knowledge $[26,27]$. The delivery of the training program in the local language understood by workers helped employees in enhancing safety related knowledge and learning [28]. Hence it is suggested that safety training influences knowledge acquisition which in turn helps in the creation of a safe workplace. This leads to the following hypotheses:

H1: The safety training influences the worker's perception of knowledge acquisition which helps in the creation of a safe work environment

\subsection{Safety training and employee behavior}

Safety training enhances the knowledge of risks at the workplace. During one's career, employees may work on different projects, departments, jobs, and companies. Each new stint adds value to employee knowledge and experience. Every company has its own unique safety training, expected safety behavior, and safety culture prevalent in the organization. This will depend upon management support and its adherence to safety training and practices. The number of years of experience, trade, project type, organization type, and worksite environment also have an impact on the worker's behavior and perception of safety post safety training [29]. Employee's post safety training emerged with a better intent to behave safely in the construction industry but without caring much about safety as a key issue [11]. Safety training in the petroleum industry helped employees to identify errors and use proper tools to change unsafe behaviors and thereby reduce accidents [30]. Safety training helped employees change from negative behavior to a more actively engaged individual towards safety-related aspects in an organization in the oil and gas industry [31]. The supervisor and worker in a factory need to maintain a cordial relationship. All safetyrelated issues ought to be discussed amongst all stakeholders on the shop floor, and the best course of action can further be implemented. The culture of an organization plays a key role in ensuring such healthy interactions between the workforce. A psychological contract between the supervisors and workers creates a mutual safety obligation and enhances the adoption of safe practice at the workplace [32]. Hence it is propounded that safety training helps in the alteration of supervisor behavior and towards the creation of a safe work environment. This leads to the following hypotheses:

H2: The safety training alters the supervisor's behavior further helping in the creation of a risk-free work environment.

\subsection{Safety training and organization safety work culture}

Workers develop greater awareness of safety risks and an intention to behave safely at the workplace post safety training. Schwatka et al. [33] observed an improvement in the supervisor's understanding of safety practices post safety training in the construction industry. Worker attitude is greatly influenced by a mix of individual demographic characteristics 
as well as the type of training undertaken. Training as a single medium may not have a significant impact on changing worker's attitudes to workplace safety. Apart from training, supervisor commitment to safety also helps create a healthy safety culture. Safety compliance in an organization was significantly related to management commitment, safety training and safety regulations [34]. The management commitment is showcased by ensuring that all safety-related communication is disseminated to the workforce promptly. The top-down communication of work-related safety information from a supervisor to the worker helps in improving the workplace safety perception. The perceptions are further strengthened if the worker feels comfortable discussing safety-related issues with the supervisor [35]. A positive correlation was observed between post safety training and health and safety in the ready-made garments industry [36]. The prevalent organizational culture also helps in reinforcing safety perceptions. Leaders need to constantly engage with workers and communicate on the importance of workplace safety. Empowering leaders encourage workers to take part in discussions and decision making on safety-related aspects. This helps in creating a culture of knowledge sharing and alterations of behavior towards safety compliance [37]. The motivation from peers, appreciation at workplace, rewards, and incentives for safe behavior along with proper incident and investigation reporting results into positive perception towards the safety culture.

Employees must also be able to report unsafe or unhealthful workplace conditions or hazards to a supervisor without any fear of reprisal, which can help in the creation of a safe work environment. The presence of a supportive supervisor helps in reducing worker injuries and in the creation of a safe work environment [38]. A safe work environment is also an outcome of an organizational safety culture. The safety culture is created over some time by the leadership support and commitment to safety practices in the organization. Employees adhere to safety practices and compliance based on the prevalent safety culture. Supervisors also adapt their behaviors in line with the safety culture. Organizations with conducive safety culture are more likely to develop a positive safety climate and work environment at the workplace [39]. To ensure safety compliance at the workplace, the supervisor is expected to communicate with the workers keeping the degree of noncompliance in mind. The quality of communication of a supervisor depends on various intrapersonal factors. Guris et al. [40] postulated that with repeated and focused training, the participants could develop assertive behaviors, which could greatly benefit workplace performance. Hence it is suggested that safety training helps in the creation of safety culture in an organization. This leads to the following hypotheses:

H3: Safety training influences the perception of employees towards the safe work culture.

\section{MATERIALS AND METHODS}

\subsection{Survey design, sample size, and participation}

This study was conducted for the automotive OEMs enterprises in India during the period of January- August 2019. Before the data collection, the automotive OEM component manufacturing regions and clusters were identified through the records published by the Centre for Monitoring Indian Economy (CMIE) and Ministry of Labor and Employment, India. The basic information about the components manufactured, EHS practices (if available), human resource (HR) person, supervisor's role and responsibility, etc., were collected and compiled which results in further sorting of the manufacturing units for our study. The HRs of units were contacted through email or telephone as per their availability describing the goal of the study and their volunteer participation and support towards the data collection for the study. It was ensured to the HR persons and supervisors that the name and details of the company as well as the participants will be kept anonymous and will be used only for research purposes. The HRs were requested to support in circulating the questionnaire for data collection to the supervisor or mid-level managers engaged in safety or EHS related profile for the company and emphasize that participation as voluntary, offer assurance that their responses would be kept confidential. Only supervisors or EHS managers who had undergone at least one-day training related to safety or EHS in the past three years were considered for the survey.

The contacts were established through the different modes to HR managers or senior EHS officers from 63 different manufacturing OEM automotive units from the DelhiNational Capital Region (NCR) and Pune- Nashik - Kolhapur from Western region agreed to participate in the survey. Of these 63 units selected, 48 units out of them agreed to participate in the survey. In total, 146 filled questionnaire responses were received from the senior supervisors or EHS and safety managers involved in the supervision of safety role from different departments in their respective units. After scrutiny of the questionnaires, only 129 valid questionnaire responses were considered for further analysis in the study.

Safety training has a linkage with the formation of safety attitudes. Grau et al. [41] in their study found a negative relation between training and safety. This was attributed to the attitudes of people who underwent additional training but did not have a favorable safety attitude. Thus, the number of safety training may influence the attitudes of workers toward safety provided they have favorable personal safety attitudes. Orpen's [42] research further postulates that additional training is positively associated with the formation of a favorable attitude as long as the participants being trained, found usefulness in the training program. Therefore, in this study, the parameter for evaluating the influence of the training was considered in terms of the number of training attended by the supervisors under the scope defined for the study.

For detailed analysis to study the influence of post- safety training on the supervisors' learning process, behavior towards safety and development of a safe work environment, a pretested and validated structured questionnaire has been designed on the different measures for each category. The scope of the questionnaire response was limited to those automotive component OEMs unit supervisors or EHS managers involved in the supervision role at their organization who have attended or completed any safety-related training (which includes HIRA training, supervisory roles and safety management etc.,) in the past three years from the date of survey irrespective of their gender. The questions were mainly close-ended, where the participants were asked to provide their agreement level with each item on a 5-point Likert scale (1= strongly disagree, $5=$ Strongly agree) [43]. The questionnaire was divided into four sections: respondent's demographics, and three measures, namely, learning process perception, 
behavior perception and safe work environment perception post-training. The measures were adapted from the original framework of the human factor's knowledge framework [44], [45]. The items for each measure were adapted based on survey questions developed for safety measurement and improvement [46]. The items for each measure were prepared after the closed brainstorming session with HR managers and safety officers through the expert's opinion method using a focus group discussion approach during the planning phase of the questionnaire design.

For testing the clarity and appropriateness of the questions in a questionnaire, a pilot survey has been undertaken. The pilot was conducted for the 23 respondents from the mid-level managers in Pune region OEM units. To determine the reliability and consistency of the questionnaire, a Cronbach alpha $(\alpha)$ is used. The questionnaire and statements were modified in light of the results of the pilot study and implemented for a detailed survey across different automotive OEMs. The Cronbach- $\alpha$ is found to be 0.905 which dictates the high reliability of the questionnaire.

\subsection{Measures}

3.2.1 Safety training and knowledge acquisition process perception of supervisors

The perception of the post-training learning process and application of skills acquired post-training was adapted from Carder and Ragan [46] and as an outcome of the discussion with experts as explained in an earlier section. This measure consists of six different constructs which include: acquired learning process e.g., "understanding the linkages between my job responsibility and organizational safety program", "more vigilant about the safety", ability to understand and identify risks and hazards associated with operations and activities", "supervisors' confidence in responding to emergencies", "correlate it with laws and regulations". Participants indicated their level of perception on 5-point Likert scale $(1=$ strongly disagree, $5=$ strongly agree), with Cronbach $\alpha$ of 0.81 showing internal consistency in the present study.

\subsubsection{Safety training and behavior perception of supervisors}

The perception of self- behavioral change towards safety issues in organization post-training was assessed by five items as adapted and modified from the Carder \& Ragan [46] survey-based safety measurement during discussion and inputs received from the expert's workshop. These five items were focused on the change in behavior of supervisors related to self-actions, colleagues and co-workers, and the realization of the importance of reports related to safety and incidents The construct items include: "regular cautioning to fellow employees about the unsafe working environment to create awareness among them also", "encourages self and coworkers also to report incidents irrespective of types and nature of magnitude to the concerned authority", "selfintuition towards the ownership and maintenance of the work equipment's to ensure safer operations", "seriously taking the suggestions provided by peers and co-workers on process safety improvement", "involvement in incident reporting and investigations seriously". All these item responses were measured on the scale of $1=$ "strongly disagree" and 5= "Strongly Agree." The Cronbach $\alpha$ in the present study was 0.79 .
3.2.3 Safety training and Safe work culture perception of supervisors

To explore the hypothesis that the post-training has helped them in developing a safe work environment and safety culture under their operation ambit, a five-item scale was developed through the feedback received from the experts and practitioners. The perception of the supervisors in this section refers to explore how they perceive about the knowledge, learning, and self- behavioral change with the overall development of safe work environment and safety culture that has improved the quality and created a productive and inspiring environment at the workplace. The items for this construct include: "management concern about the safety outcomes as important as to business outcomes"; "recognition of safe work behavior by the senior supervisors and managers"; "risks and hazards arising due to change in the process are adequately addressed, reviewed and implemented"; "selfconfidence in the safety improvement process at the workplace", and "post-training suggestions has resulted in a safer environment at the workplace". The Cronbach $\alpha$ in the present study was 0.78 , and the item responses were measured on the same 5- point scale ranging from 1= "strongly disagree" to $5=$ "strongly agree" as discussed in earlier sections.

The other section of the questionnaire was to verify the outcomes of the post-training related to safety from the supervisors. This final section explores the type of suggestions provided to the organization by the supervisors related to their process and operations post-training. The suggestions provided by the supervisors were categorized as major, minor, or a suggestion but having no significant risk. This further helps us in assessing and validating supervisors' knowledge and skills acquired through training.

\subsubsection{The model framework of the study}

To study "the effectiveness of post- safety training on employee level perception on their knowledge acquisition and learning process, change in their behavior and development of safe work environment," was modeled using multiple linear regression. In this model, the likelihood of post safety training influencing knowledge, behavior, and a safe work environment can be predicted. The model $\mathrm{R}$ and $\mathrm{R}^{2}$ were used to estimate the model fit and variance explanation in $\mathrm{Y}$ by the model, respectively.

\subsubsection{Statistical analysis}

The data collected from the questionnaire-based survey was analyzed using SPSS vs. 21.0 (IBM). Data were tabulated, categorized, coded, and decoded according to the purposes of the study. Descriptive statistics were applied to investigate the demographic characteristics of the respondents. The demographic variables were gender, age, marital status, average working hours at the unit, working experience, related education in EHS or safety, relevant field experience in EHS or safety domain, and the number of safety training (including HIRA training, safety supervisor's role, safe handling etc.) by the supervisors and EHS/ safety managers considered in the analysis. Cronbach $\alpha$ was applied to calculate the internal consistency of the scales measuring the knowledge process, self- behavioral change, and overall development of safe work and safety culture perceptions. The data were checked for normality using Shapiro- Wilk's test of normality. Only the variables Education in EHS and EHS related work experience were found to be non- normal. After the normality test of the data in the regression model, a multicollinearity test was 
performed to determine the existence of similarity between the independent variables in the model. The variance inflation factor (VIF) is used to detect the multicollinearity in the data. The value of VIF results were found to be between 1 to 10 for all the independent variables stating no correlation between independent variables, a prerequisite for a good regression model. Also, the data was analyzed for its adequacy using KMO-MSA (Kaiser- Meyer- Olkin- Measure of Adequacy) for testing the adequacy of data for model testing. The KMOMSA test reveals a value of 0.84 dictating the high adequacy of the data.

To evaluate the relationship between different variables, a Pearson's $r$ correlation coefficient was performed. The Pearson's- correlation (r) between independent (variables for main attributes viz., age, work experience, gender, working hours, safety training, perceptions of the learning process, knowledge acquisition, self- behavior change, and safe environment culture), and independent variables (number of safety training) was performed. To explore the contribution of items and unique affecting factors that were associated with the perception, a hierarchical multiple regression analysis using the stepwise method was applied. A two-sided p-value of less than 0.05 was considered statistically significant.

\section{RESULTS}

In the present study, 129 responses from 48 units of the automotive manufacturing OEM units were considered for analysis. The responded survey results in the study include
$76 \%$ males and $24 \%$ females by gender with their mean age of 39 years ranging from 24 years to 52 years of age. The diverse respondents involved in the safety, EHS management (junior to mid-level), and at the supervisor level from different OEM units are from Pune -Nashik- Kolhapur region in West of India and from Delhi- NCR from North of India, which are known industrial hubs in India. The maximum respondents have a technical graduate degree (65\%) followed by diploma degree holders $(21.7 \%)$, who took part in the survey. Out of this $61 \%$ of respondents have an education or skill certification related to the environment, health, and Safety (EHS) or safety in general. The education level plays an important part in the effectiveness of training and knowledge acquisition. Education levels of employees are significantly associated with policy awareness and compliance [47]. The participants are having a mean overall work experience of 12 years ranging from a minimum of two years to a maximum of 28 years (general work experience which may include EHS or safety experience). As discussed in the earlier section of this paper, only those respondents were covered in the survey who has attended any number of safety or EHS related training in the past three years of their tenure with the organization. The details of demographic and other variable descriptive are shown in Table 1. The survey reveals that in the total responses received, the respondents have undergone a minimum one training to a maximum of four training in the past three years related to safety or EHS profile. The different training that was completed by the participants was related to EHS and safetyrelated aspects of their work environment.

Table 1. Descriptive analysis of respondents demographic and measured variables

\begin{tabular}{|c|c|c|c|c|}
\hline Description & Frequency & Percentage & Mean (M) & SD \\
\hline \multicolumn{5}{|l|}{ Gender } \\
\hline Female & 31 & 24.0 & -- & -- \\
\hline Male & 98 & 76 & -- & -- \\
\hline Age (in Years) & & & 39 & 5.5 \\
\hline $18-24$ & 2 & 1.5 & & \\
\hline $25-31$ & 5 & 3.9 & & \\
\hline $32-38$ & 55 & 42.6 & & \\
\hline $39-45$ & 48 & 37.3 & & \\
\hline 46 and above & 19 & 14.7 & & \\
\hline \multicolumn{5}{|l|}{ Marital Status } \\
\hline Yes & 119 & 92.2 & & \\
\hline No & 10 & 7.8 & & \\
\hline \multicolumn{5}{|l|}{ Education in EHS/ Safety } \\
\hline Yes & 79 & 61.2 & & \\
\hline No & 50 & 38.8 & & \\
\hline \multicolumn{5}{|l|}{ Education Level } \\
\hline Non- TechnicalGraduate Degree & 2 & 1.6 & & \\
\hline Diploma Holder & 28 & 21.7 & & \\
\hline Technical Graduate Degree & 84 & 65.1 & & \\
\hline Post Graduate & 15 & 11.6 & & \\
\hline \multicolumn{3}{|c|}{ Overall Work Experience in the Manufacturing Sector } & 12.5 & 5.4 \\
\hline $0-2$ years & 2 & 1.6 & & \\
\hline $2-5$ years & 11 & 8.5 & & \\
\hline 5-7 years & 10 & 7.7 & & \\
\hline 7 years and above & 106 & 82.2 & & \\
\hline \multicolumn{3}{|c|}{ Related work experience in EHS or Safety field } & 5.1 & 3.8 \\
\hline \multicolumn{3}{|c|}{ Working Hours at the Plant } & 9 & 0.9 \\
\hline \multicolumn{3}{|c|}{ Number of Safety related training attended in the last three years } & 2.2 & 0.8 \\
\hline \multicolumn{3}{|c|}{ Knowledge Acquisition and Learning Process } & 3.7 & 0.6 \\
\hline \multicolumn{3}{|c|}{ Self-Behaviour Change } & 3.6 & 0.5 \\
\hline \multicolumn{3}{|c|}{ Development of Safe work Environment and Culture } & 3.4 & 0.6 \\
\hline
\end{tabular}


Table 2. Correlation coefficients of the demographic and measured variables on Perception $\left({ }^{*} \mathrm{p}<0.05\right)$

\begin{tabular}{|c|c|c|c|c|c|c|c|c|c|}
\hline & Variables & 1 & 2 & 3 & 4 & 5 & 6 & 7 & 8 \\
\hline 1 & Safety Training done & 1.0 & & & & & & & \\
\hline 2 & Education Related to EHS/ Safety & $0.5^{*}$ & 1.0 & & & & & & \\
\hline 3 & Overall Working Experience & $0.7^{*}$ & $0.5^{*}$ & 1.0 & & & & & \\
\hline 4 & Work Experience in EHS/Safety Profile & $0.6^{*}$ & $0.4^{*}$ & $0.7^{*}$ & 1.0 & & & & \\
\hline 5 & Daily Working Hours in Plant & 0.1 & 0.2 & 0.1 & 0.1 & 1.0 & & & \\
\hline 6 & Perception on Knowledge Acquisition & $0.4^{*}$ & 0.2 & $0.5^{*}$ & $0.2^{*}$ & 0.1 & 1.0 & & \\
\hline 7 & Perception on Self Behaviour Change & $0.3^{*}$ & $0.0^{*}$ & $0.3^{*}$ & $0.2^{*}$ & -0.0 & $0.6^{*}$ & 1.0 & \\
\hline 8 & Perception on training helps in developing Safe Work Culture & $0.1^{*}$ & $0.2^{*}$ & $0.2^{*}$ & 0.1 & 0.1 & $0.4^{*}$ & $0.4^{*}$ & 1.0 \\
\hline
\end{tabular}

Table 3. Results of the hierarchical multiple regression analysis for perception on knowledge, behavioral change, and development of a safe work environment, post-training by supervisors $\left({ }^{*} \mathrm{p}<0.05\right)$

\begin{tabular}{|c|c|c|c|c|c|c|c|c|}
\hline \multirow{2}{*}{$\begin{array}{c}\text { Step } \\
\text { Variables }\end{array}$} & \multicolumn{2}{|c|}{ Step 1} & \multicolumn{2}{|c|}{ Step 2} & \multicolumn{2}{|c|}{ Step 3} & \multicolumn{2}{|c|}{ Step 4} \\
\hline & $\beta$ & $t$ & $\beta$ & $t$ & $\beta$ & $t$ & $\beta$ & $t$ \\
\hline Education Related to EHS/ Safety ${ }^{i}$ & 0.31 & $2.50^{*}$ & 0.32 & $2.68^{*}$ & 0.30 & $2.47^{*}$ & 0.31 & $2.47^{*}$ \\
\hline Overall Working Experience & 0.05 & $2.21^{*}$ & 0.02 & 1.02 & 0.02 & 1.06 & 0.02 & 1.04 \\
\hline Work Experience in EHS/Safety Profile & 0.07 & $3.32^{*}$ & 0.08 & $3.91^{*}$ & 0.08 & $3.98^{*}$ & 0.08 & $3.95^{*}$ \\
\hline Daily Working Hours in Plant & 0.04 & 0.78 & 0.04 & 0.69 & 0.04 & 0.65 & 0.04 & 0.66 \\
\hline $\begin{array}{l}\text { Perception of Knowledge Acquisition } \\
\text { Perception of Self Behaviour Change }\end{array}$ & & & 0.32 & $3.27^{*}$ & $\begin{array}{c}0.38 \\
-0.11\end{array}$ & $\begin{array}{l}3.06^{*} \\
-0.84\end{array}$ & $\begin{array}{r}0.41 \\
-0.10\end{array}$ & $\begin{array}{l}2.82^{*} \\
-0.74\end{array}$ \\
\hline Perception of training helps in developing Safe Work Culture & \multirow{4}{*}{\multicolumn{2}{|c|}{$\begin{array}{c}0.55 \\
21.19^{*}\end{array}$}} & \multirow{2}{*}{\multicolumn{2}{|c|}{0.59}} & \multirow{2}{*}{\multicolumn{2}{|c|}{0.60}} & -0.04 & -0.34 \\
\hline $\mathrm{R}^{2}$ & & & & & & & \multicolumn{2}{|c|}{0.62} \\
\hline $\mathrm{F}$ & & & \multirow{2}{*}{\multicolumn{2}{|c|}{$21.25^{*}$}} & \multicolumn{2}{|c|}{$19.01^{*}$} & \multicolumn{2}{|c|}{$16.99^{*}$} \\
\hline$\Delta \mathrm{R}^{2}$ & & & & & \multicolumn{2}{|c|}{0.01} & \multicolumn{2}{|c|}{0.02} \\
\hline
\end{tabular}

Table 2 shows the correlation between different demographic and perception measured variables of the respondents. The result shows that there is a positive significant relationship between the number of safety training done with overall working experience of respondents $(\mathrm{r}=0.68$, $\mathrm{p}<0.05$ ), working experience in the field of EHS or safety ( $\mathrm{r}$ $=0.65, \mathrm{p}<0.05)$, related education in EHS or safety $(\mathrm{r}=0.50$, $\mathrm{p}<0.05)$, perception on knowledge acquisition and learning process $(\mathrm{r}=0.44, \mathrm{p}<0.05)$, perception on self- behavior change $(r=0.26, p<0.05)$ and perception on development of safe work environment $(\mathrm{r}=0.15, \mathrm{p}<0.05)$. There is a significant positive correlation between all the three perceptions of the supervisors in the study. All the demographic, as well as perception, measured variables shows an insignificant and very weak relationship with the 'daily working hours at the plant' by the supervisors. The higher correlation with age, working experience on EHS profile, overall working experience of the respondents and the number of safety training attended in last three years indicates that with the increase in age as well as experience, the supervisors tend to attend more training related to safety for their enhancement of knowledge and skills.

For the explanation of the dependent variable (i.e., safety training), based on variation in other variables (demographic and perception measured variables), hierarchical multiple regression analysis in a stepwise method was performed.

The results depicted in Table 3 reveal that the knowledge acquisition, learning process, and employee involvement regarding risks and hazard identification $(\beta=0.317, \mathrm{t}=3.26, \mathrm{p}$ $<0.05$ ) positively affected the perceived effectiveness of post safety training by the supervisors. The regression model, Ftest for the influence of post- safety training on all the perceptions by the supervisors is fit and significant. The $\mathrm{R}^{2}$ value for the model is 0.62 , which is very high and significant at $p<0.05$. The results indicate that statistically the post- safety training has no significant contribution towards the perceived self- behavior change $(\beta=-0.115, p>0.05)$ and development of safe work environment $(\beta=-0.104, p>0.05)$. It shows that it is related to education in EHS and safety, working experience in the field of safety or EHS and knowledge of the supervisors which plays a significant role in the effectiveness of safety training and development of a safe work environment along with the change in behavior towards the safety.

The variance explained indicates that the influence of postsafety training accounted for $4 \%$ of the knowledge acquired and learning process $[\mathrm{F}(8,129)=21.35, \mathrm{p}<0.05], 1.1 \%$ by the behavioral change $[F(9,129)=19.01, p<0.05]$ and $2 \%$ perception on development of safe work culture and environment at workplace $[\mathrm{F}(10,129)=16.99, \mathrm{p}<0.05]$. In step 1, the demographic variables viz., overall working experience of supervisors; working experience in EHS or safety domain; and education in EHS or safety shows significant contribution towards the influence of safety training. The study reveals the acceptance of hypothesis H1 i.e., post safety training influences the knowledge acquisition of the employees and the rejection of hypotheses $\mathrm{H} 2$ and $\mathrm{H} 3$. Therefore, the safety training definitely changes the learning process but its influence on behavioral changes and development of safe work culture cannot be proved statistically.

\section{DISCUSSION}

The present study evaluates the supervisor's perception of knowledge acquisition, their behavioral change, and a safe work environment for safety training attended in Indian automotive OEM units. It was found that the demographic variables that affect the safety training effectiveness aregender, education in the EHS field, overall working experience, and work experience in safety/ EHS profile. The results were similar to the research in the construction field which states that it is the training and experience of the workers that are instrumental in identifying and assessing risks 
associated with the job [48]. Similar results were also revealed by Wong et al. [49], exploring that there is a positive relationship between the enhancement of knowledge and the academic background of the trainees.

The influences of the effectiveness of post- safety training were evaluated from the stated perceptions of supervisors. The positive and significant relationship between the different variables indicates that safety training has a positive impact on the perception of the supervisors. The supervisors believe that safety training has helped them in improving their knowledge level and updated their learning towards the risks and hazards identification at their workplace. The positive relationship also has resulted in their change in behavior about the safety and risks associated with their jobs. On the other hand, it was also found that the influence of post safety training has an insignificant contribution to the perception of the development of a safe work environment and culture post-training. The findings are supported by Wong et al. [49], who found that knowledge enhancement has no connection with the reduction of accidents. But there are postulates from other researches also that post safety training has resulted in a significant change in behavior and attitudes of the trainees and personal safety $[50,51]$ which needs to be explored further.

The hypothesis testing through multiple regression model reveals support only to the first hypothesis (H1). The other two hypotheses ( $\mathrm{H} 2$ and $\mathrm{H} 3$ ) were rejected based on a lack of statistical evidence of significance. Surprisingly, our study reveals that the post- safety training to the supervisors has resulted in the knowledge acquisition and learning of the risks and hazards at their workplace but did not result in the behavioral change and development of a safe work environment significantly. The model reveals that it is the EHS profile work exposure and education in the EHS domain of safety, and additionally, the knowledge acquired through the training which influences the effectiveness of the training program. It is in line with the earlier research in the construction sector which has proved that training does not significantly change the attitude or behavior of the worker [11, 52]. Although many past researches in the same field has resulted that it is the training that influences the behavior of the workers towards safety [53]. But contrastingly, the results for manufacturing OEM enterprises are different in our study.
For the perception of the supervisor's knowledge process through safety training, it was found that the supervisors believe there is a positive significant contribution of postsafety training. It develops more confidence in the supervisors to respond in emergencies and has enhanced the level of understanding to identify hidden risks and hazards related to the workplace. For the self-behavioral change, it is found that the workers take more ownership of the equipment at the workplace and see the importance of the maintenance for ensuring the safety of the workers.

The employees perceived that safe work behavior is recognized in their workplace through incentives and motivations. But to develop a safety culture overall, there are other driving and regulating factors along with the supervisors' training and behavioral change [54]. The management involvement and concern about the importance of safety as equivalent to business outcomes are more important [55]. This factor has been perceived as insignificant in our study. The other factors which are important and required for safety culture and environment at the workplace are review process, change management process of the company, incident, and investigation reporting process and continual improvement of the system [56]. Another factor is how the suggestions provided by the supervisors are handled and considered by the senior supervisors or managers to implement at the workplace. Our study shows that after attending the training, supervisors have given an average of three suggestions in their organization to ensure a safe work environment considering both major and minor suggestions depending on the risks. Out of which on average, two of the suggestions were implemented by the management. A few of the suggestions provided by the supervisors are summarized in Table 4. Maximum suggestions have been given under the heading of identification of workplace risks and hazards such as overloading of materials, low ventilation, rotating parts, fumes, noise, etc. Many respondents have also suggested designing motivational incentives for reporting incidents and risks, and it is required for sustained safety practices and behavior change. Other suggestions are in the areas of legal compliances, fire safety, emergency responses etc., as summarized in Table 4.

Table 4. Summary of suggestions given by the supervisor's post- safety training in a year

\begin{tabular}{|c|c|}
\hline Some of the Suggestions by the respondents to safety & $\begin{array}{c}\text { Number of } \\
\text { Respondents Given } \\
\text { suggestions }\end{array}$ \\
\hline Legal Compliance under EHS & 43 \\
\hline Management role and intervention to ensure safety & 19 \\
\hline Motivational incentives for reporting incidents and risks, appreciation at work & 56 \\
\hline LOTO (Lock- Out and Tag- Out) system in place & 16 \\
\hline Fumes and chemical handling related at the shop floor & 21 \\
\hline Hazardous chemical handling and waste management related & 23 \\
\hline Tool monitoring and routine inspection and maintenance reporting & 72 \\
\hline Toolbox meetings and awareness through videos and signage, Improving communication among the co-workers & 39 \\
\hline Appropriate signage at appropriate places & 81 \\
\hline Electric overhead traveling crane (EOT Crane) inspection, maintenance, and compliance regulation & 32 \\
\hline PPE requirements and Procurements & 69 \\
\hline $\begin{array}{l}\text { Identification of Workplace risks and hazards e.g., Rotating parts, Sharp edges, working at heights, overloading of } \\
\text { materials, proper storage, welding fumes, congested place, low ventilation, noise at work, packed chambers, etc., }\end{array}$ & 102 \\
\hline Fire safety and emergency plans & 61 \\
\hline Mock drills and regular audits & 29 \\
\hline Preparation of emergency response teams, awareness & 18 \\
\hline Safety guidelines to forklift drivers, guarding of Machines & 12 \\
\hline Visitors gate pass, No entry zone, and markings for outsiders and yellow markings for movement & 19 \\
\hline
\end{tabular}




\section{CONCLUSIONS}

The results of our study reveal that there is a direct relation to safety training when it comes to imparting knowledge skills and learning processes for the employees, and it has its advantage. But the study does not support the fact that safety training has resulted in the change in behavior of the supervisors who work at the grassroots level and who first interacts with the co-workers in case of any incident that happens on the shop floor.

The results show that it's the supervisor's overall experience and the knowledge he has acquired through his safety-related education and training that influences the effectiveness and implementation of safety on the shop floor most. The study also highlights that safety training has no influence on the development of a safe work environment at the workplace. It is the educational background of safety-related training exposure and work experience of the supervisors in the field of safety and health, which helps in ensuring a safe work environment by the supervisors. The supervisor's experience in safety is a crucial factor and is obvious too. Based on the results, it is advocated that companies give emphasis on the safety-related work experience of the supervisors blending it with the skill development program periodically if having serious concerns about the safety issues in their premises. Organizations can also focus on creating a conducive safety culture with support from the top management. Safe work behavior is an outcome of positive safety culture [57]. The study recommends different behavioral related training and management approaches at the shop floor for the employees, which will ensure the creation of a safe work environment.

The limitation of the study relates to its relative focus on a single sector with a single cohort of the designation of employees for a particular geographic region. Future studies should aim to investigate the factors responsible as well as certain other sudden factors such as equipment failures, construction quality etc., for the effectiveness of the training at the different levels of job roles and cohorts of responsibilities from shop floor employees to senior management level. The study advocates the importance of the training for the workers but also suggests having a selection of the appropriate method of training and a preliminary need assessment should be done to identify the type of training required for their workers and as per the operations.

\section{REFERENCES}

[1] Badri, A., Boudreau-Trudel, B., Souissi, A.S. (2018). Occupational health and safety in the industry 4.0 era: A cause for major concern? Safety Science, 109: 403-411. https://doi.org/10.1016/j.ssci.2018.06.012

[2] Dorman, P. (2000). The Economics of Safety, Health, and Well-Being at Work: An Overview. https://www.ilo.org/wcmsp5/groups/public/-ed_protect/---protrav/-safework/documents/publication/wcms_110382.pdf, accessed on May 30, 2019.

[3] ILO. (1999). ILO Estimates Over 1 Million WorkRelated Fatalities Each Year. https://www.ilo.org/global/about-theilo/newsroom/news/WCMS_007969/lang--en/index.htm.

[4] Amponsah-Tawiah, K., Mensah, J. (2016). Occupational health and safety and organizational commitment:
Evidence from the Ghanaian mining industry. Safety and Health at Work, 7(3): 225-230. https://doi.org/10.1016/j.shaw.2016.01.002

[5] Kim, Y., Park, J., Park, M. (2016). Creating a culture of prevention in occupational safety and health practice. Safety and Health at Work, 7(2): 89-96. https://doi.org/10.1016/j.shaw.2016.02.002

[6] Amponsah-Tawaih, K., Adu, M.A. (2016). Work pressure and safety behaviors among health workers in Ghana: The Moderating Role of Management Commitment to Safety. Safety and Health at Work, 7(4): 340-346. https://doi.org/10.1016/j.shaw.2016.05.001

[7] Konijn, A.M., Lay, A.M., Boot, C.R.L., Smith, P.M. (2018). The effect of active and passive occupational health and safety (OHS) training on OHS awareness and empowerment to participate in injury prevention among workers in Ontario and British Columbia (Canada). Safety Science, 108: 286-291. https://doi.org/10.1016/j.ssci.2017.12.026

[8] Vigoroso, L., Caffaro, F., Cavallo, E. (2018). Occupational safety and visual communication: Usercentred design of safety training material for migrant farmworkers in Italy. Safety Science, 121: 562-572. https://doi.org/10.1016/J.SSCI.2018.10.029

[9] Aziz, S.F.A., Osman, F. (2019). Does compulsory training improve occupational safety and health implementation? The case of Malaysian. Safety Science, 111: 205-212. https://doi.org/10.1016/j.ssci.2018.07.012

[10] Kim, W.Y., Cho, H.H. (2016). Unions, health and safety committees, and workplace accidents in the Korean manufacturing sector. Safety and Health at Work, 7(2): 161-165. https://doi.org/10.1016/j.shaw.2016.02.005

[11] Loosemore, M., Malouf, N. (2019). Safety training and positive safety attitude formation in the Australian construction industry. Safety Science, 113: 233-243. https://doi.org/10.1016/j.ssci.2018.11.029

[12] Başağa, H.B., Temel, B.A., Atasoy, M., Yıldırım, İ. (2018). A study on the effectiveness of occupational health and safety trainings of construction workers in Turkey. Safety Science, 110: 344-354. https://doi.org/10.1016/j.ssci.2018.09.002

[13] Peng, L., Chan, A.H.S. (2019). A meta-analysis of the relationship between ageing and occupational safety and health. Safety Science, 112: 162-172. https://doi.org/10.1016/j.ssci.2018.10.030

[14] Cruz, I., Huerta-Mercado, R. (2015). Occupational safety and health in Peru. Annals of Global Health, 81(4): 568575. https://doi.org/10.1016/j.aogh.2015.08.027

[15] Byrd, J., Gailey, N.J., Probst, T.M., Jiang, L. (2018), Explaining the job insecurity-safety link in the public transportation industry: The mediating role of safetyproduction conflict. Safety Science, 106: 255-262. https://doi.org/10.1016/j.ssci.2016.11.017

[16] Hadjimanolis, A., Boustras, G., Economides, A., Yiannaki, A., Nicolaides, L. (2015). Work attitudes and safety performance in micro-firms - Results from a nationwide survey: (the opinion of the employees). Safety Science, 80: 135-143. https://doi.org/10.1016/j.ssci.2015.07.026

[17] Gravina, N.E., King, A., Austin, J. (2019). Training leaders to apply behavioral concepts to improve safety. Safety $\quad$ Science, $\quad 112$ : 66-70. https://doi.org/10.1016/j.ssci.2018.10.013

[18] Provan, D.J., Rae, A.J., Dekker, S.W.A. (2019). An 
ethnography of the safety professional's dilemma: Safety work or the safety of work? Safety Science, 117: 276-289. https://doi.org/10.1016/j.ssci.2019.04.024

[19] Pandit, B., Albert, A., Patil, Y., Al-Bayati, A.J. (2019). Impact of safety climate on hazard recognition and safety risk perception. Safety Science, 113: 44-53. https://doi.org/10.1016/j.ssci.2018.11.020

[20] Korkmaz, S., Park, D.J. (2018). Comparison of safety perception between foreign and local workers in the construction industry in Republic of Korea. Safety and Health at Work, 9(1): 53-58. https://doi.org/10.1016/j.shaw.2017.07.002

[21] Ram, T., Chand, K. (2016). Effect of drivers' risk perception and perception of driving tasks on road safety attitude. Transportation Research Part F: Traffic Psychology and Behaviour, 42: 162-176. https://doi.org/10.1016/j.trf.2016.07.012

[22] Ma, Q., Yuan, J. (2009). Exploratory study on safety climate in Chinese manufacturing enterprises. Safety Science, 47(7): 1043-1046. https://doi.org/10.1016/j.ssci.2009.01.007

[23] Oah, S., Na, R., Moon, K. (2018). The influence of safety climate, safety leadership, workload, and accident experiences on risk perception: A study of Korean manufacturing workers. Safety and Health at Work, 9(4): 427-433. https://doi.org/10.1016/j.shaw.2018.01.008

[24] Mattson Molnar, M., Von Thiele Schwarz, U., Hellgren, J., Hasson, H., Tafvelin, S. (2019). Leading for safety: A question of leadership focus. Safety and Health at Work, 10(2):

$180-187$. https://doi.org/10.1016/j.shaw.2018.12.001

[25] Rodriguez, A., Hagevoort, G.R., Leal, D., Pompeii, L., Douphrate, D.I. (2018). Using mobile technology to increase safety awareness among dairy workers in the United States. Journal of Agromedicine, 23(4): 315-326. https://doi.org/10.1080/1059924X.2018.1502704

[26] Dzeng, R.J., Hsueh, H.H., Chang, R.N. (2015). 3D gamebased training system for hazard identification on construction site. 2015 12th International Conference on Fuzzy Systems and Knowledge Discovery (FSKD), Zhangjiajie, pp.

https://doi.org/10.1109/FSKD.2015.7382339

[27] Mohd, N.I., Ali, K.N., Shafaghat, A. (2015). Construction player's perception of training approach using serious game-a pilot study. Jurnal Teknologi, 77(16): 137-143. https://doi.org/10.11113/jt.v77.6410

[28] del Puerto, C.L., Fontan-Pagan, J.J., Molina-Bas, O.I., Mrozowski, T.L. (2016). Safety training on warehouse worker hazards for structural steel Latino workers: Phase 2 Implementation and Assessment. 2016 ASEE Annual Conference \& Exposition, New Orleans, Louisiana. https://doi.org/10.18260/p.26130

[29] Xu, S., Zhang, M., Hou, L. (2019). Formulating a learner model for evaluating construction workers' learning ability during safety training. Safety Science, 116: 97107. https://doi.org/10.1016/j.ssci.2019.03.002

[30] Khan, S., Yaqoob, S. (2019). Human factors and performance: Reducing errors and improving safety. In Abu Dhabi International Petroleum Exhibition \& Conference. Society of Petroleum Engineers, pp. 11-14. https://doi.org/10.2118/197329-MS

[31] Mazrouei, M.A., Khalid, K., Davidson, R., Abdallah, S. (2019). Impact of organizational culture and perceived process safety in the UAE oil and gas industry. The
Qualitative Report, 24(12): 3215-3238.

[32] Newaz, M.T., Davis, P., Jefferies, M., Pillay, M. (2019). The psychological contract: A missing link between safety climate and safety behaviour on construction sites. Safety Science, 112: 9-17. https://doi.org/10.1016/j.ssci.2018.10.002

[33] Schwatka, N.V., Goldenhar, L.M., Johnson, S.K., Beldon, M.A., Tessler, J., Dennerlein, J.T., Fullen, M., Trieu, H. (2019). A training intervention to improve frontline construction leaders' safety leadership practices and overall jobsite safety climate. Journal of Safety Research, 70: 253- 262. https://doi.org/10.1016/J.JSR.2019.04.010

[34] Subramaniam, C., Shamsudin, F.M., Zin, M.L.M., Ramalu, S.S., Hassan, Z. (2016). Safety management practices and safety compliance in small medium enterprises: Mediating role of safety participation. AsiaPacific Journal of Business Administration, 8(3): 226244. https://doi.org/10.1108/APJBA-02-2016-0029

[35] Huang, Y., Sinclair, R.R., Lee, J., McFadden, A.C., Cheung, J.H., Murphy, L.A. (2018). Does talking the talk matter? Effects of supervisor safety communication and safety climate on long-haul truckers' safety performance. Accident Analysis \& Prevention, 117: 357-367. https://doi.org/10.1016/j.aap.2017.09.006

[36] Zaman, F. (2019). Identifying the Importance of Workplace Health and Safety Training in Bangladesh. In European Conference on Management, Leadership \& Governance (pp. 409-416). Academic Conferences International Limited.

[37] Lee, Y.H., Lu, T.E., Yang, C.C., Chang, G. (2019). A multilevel approach on empowering leadership and safety behavior in the medical industry: The mediating effects of knowledge sharing and safety climate. Safety Science, $\quad 117: \quad 1-9$. https://doi.org/10.1016/j.ssci.2019.03.022

[38] Yanar, B., Lay, M., Smith, P.M. (2019). The interplay between supervisor safety support and occupational health and safety vulnerability on work injury. Safety and Health at Work, 10(2): 172-179. https://doi.org/10.1016/J.SHAW.2018.11.001

[39] Petitta, L., Probst, T.M., Barbaranelli, C., Ghezzi, V. (2017). Disentangling the roles of safety climate and safety culture: Multi-level effects on the relationship between supervisor enforcement and safety compliance. Accident Analysis \& Prevention, 99: 77-89. https://doi.org/10.1016/j.aap.2016.11.012

[40] Guris, R.J.D., Duarte, S.S., Miller, C.R., Schiavi, A., Toy, S. (2019). Training novice anaesthesiology trainees to speak up for patient safety. British Journal of Anaesthesia, 122(6): 767-775. https://doi.org/10.1016/j.bja.2019.01.017

[41] Grau, R., Martínez, I.M., Agut, S., Salanova, M. (2002). Safety attitudes and their relationship to safety training and generalised self-efficacy. International Journal of Occupational Safety and Ergonomics, 8(1): 23-35. https://doi.org/10.1080/10803548.2002.11076512

[42] Orpen, C. (1994). The effect of time-management training on employee attitudes and behavior: A field experiment. The Journal of Psychology, 128(4): 393-396. https://doi.org/10.1080/00223980.1994.9712743

[43] Atombo, C., Wu, C., Tettehfio, E. O., Nyamuame, G.Y., Agbo, A.A. (2017). Safety and health perceptions in work-related transport activities in Ghanaian industries. Safety and Health at Work, 8(2): 175-182. 
https://doi.org/10.1016/j.shaw.2016.10.002

[44] Ahram, T.Z., Karwowski, W., Andrzejczak, C. (2012). Human factors in knowledge management: Building better systems by employing human systems integration methods. In, Ordóñez de Pablos, P. (Ed.), Electronic Globalized Business and Sustainable Development Through IT Management: Strategies and Perspectives, IGI Global, pp. 1666-1685. https://doi.org/10.4018/9781-61520-623-0.ch003

[45] Hejduk, I., Tomczyk, P. (2015). Young workers' occupational safety knowledge creation and habits. Procedia Manufacturing, 3: 395-401. https://doi.org/10.1016/j.promfg.2015.07.184

[46] Carder, B., Ragan, P.W. (2003). A survey-based system for safety measurement and improvement. Journal of Safety Research, 34(2): 157-65. https://doi.org/10.1016/S0022-4375(03)00007-0

[47] Chua, H.N., Wong, S.F., Low, Y.C., Chang, Y. (2018). Impact of employees' demographic characteristics on the awareness and compliance of information security policy in organizations. Telematics and Informatics, 35(6): 1770-1780. https://doi.org/10.1016/j.tele.2018.05.005

[48] Sacks, R., Perlman, A., Barak, R. (2013). Construction safety training using immersive virtual reality. Construction Management and Economics, 31(9): 10051017. https://doi.org/10.1080/01446193.2013.828844

[49] Wong, F., Chan, S., Tse, R., Love, P. (2000). Improving safety knowledge through training - the case of Hong Kong. Journal of Safety Research, 33(2): 259-276.

[50] Shin, M., Lee, H.-S., Park, M., Moon, M., Han, S. (2014). A system dynamics approach for modeling construction workers' safety attitudes and behaviors. Accident Analysis \& Prevention, 68: 95-105. https://doi.org/10.1016/j.aap.2013.09.019

[51] Tam, V.W.Y., Fung, I.W.H. (2011). Tower crane safety in the construction industry: A Hong Kong study. Safety Science, 49(2): 208-215 https://doi.org/10.1016/j.ssci.2010.08.001

[52] Rodríguez-Garzón, I., Lucas-Ruiz, V., Martínez-Fiestas, M., Delgado-Padial, A. (2015). Association between perceived risk and training in the construction industry. Journal of Construction Engineering and Management, 141(5): 04014095 . https://doi.org/10.1061/(ASCE)CO.1943-7862.0000960

[53] Lingard, H., Yesilyurt, Z. (2003). The effect of attitudes on the occupational safety actions of Australian construction workers: The results of a field study. Journal of Construction Research, 4(1): 59-69. https://doi.org/10.1142/S1609945103000303

[54] Hussain, G., Batool, I., Kanwal, N., Abid, M. (2019). The moderating effects of work safety climate on sociocognitive factors and the risky driving behavior of truck drivers in Pakistan. Transportation Research Part F: Traffic Psychology and Behaviour, 62: 700-715. https://doi.org/10.1016/j.trf.2019.02.017

[55] Haslam, C., O’Hara, J., Kazi, A., Twumasi, R., Haslam, R. (2016). Proactive occupational safety and health management: Promoting good health and good business. Safety Science, 81: 99-108. https://doi.org/10.1016/j.ssci.2015.06.010

[56] Kontogiannis, T., Leva, M.C., Balfe, N. (2017). Total safety management: Principles, processes and methods. Safety Science, 100: 128-142. https://doi.org/10.1016/j.ssci.2016.09.015

[57] Clarke, S. (2000). Safety culture: Under-specified and overrated? International Journal of Management Reviews, 2(1): 65-90. https://doi.org/10.1111/14682370.00031

\section{NOMENCLATURE}

$\begin{array}{ll}\text { CMIE } & \text { Centre for Monitoring Indian Economy } \\ \text { EHS } & \text { Environment, Health and Safety } \\ \text { HIRA } & \text { Hazard Identification and Risk Analysis } \\ \text { HR } & \text { Human Resource } \\ \text { HIV } & \text { Human Immunodeficiency virus } \\ \text { ILO } & \text { International Labor Organization } \\ \text { M } & \text { Mean value } \\ \text { NCR } & \text { National Capital region } \\ \text { OEM } & \text { Original Equipment Manufacturing } \\ \text { OSH } & \text { Occupational Safety and Health } \\ \text { p } & \text { p-value } \\ \text { PPE } & \text { Personal Protective Equipment } \\ \text { r } & \text { Coefficient of correlation } \\ \text { SD } & \text { Standard Deviation }\end{array}$

\section{Greek symbol}

$\beta \quad$ variable 